\title{
CRISPR/Cas9-mediated gene knockout and interallelic gene conversion in human induced pluripotent stem cells using non-integrative bacteriophage-chimeric retrovirus-like particles
}

Joffrey Mianné ${ }^{1}$, Amel Nasri ${ }^{1}$, Chloé Nguyen Van ${ }^{1}$, Chloé Bourguignon ${ }^{1}$, Mathieu Fieldès ${ }^{1}$, Engi Ahmed ${ }^{1}$, Christine Duthoit ${ }^{2}$, Nicolas Martin², Hugues Parrinello ${ }^{3,4}$, Anaïs Louis ${ }^{3,4}$, Alexandra Iché2 ${ }^{2}$, Régis Gayon², Florine Samain ${ }^{2}$, Lucille Lamouroux ${ }^{2}$, Pascale Bouillé ${ }^{2}$, Arnaud Bourdin ${ }^{5}$, Said Assou ${ }^{1}$ and John De Vos ${ }^{1,6^{*}}$ (DD

\begin{abstract}
Background: The application of CRISPR/Cas9 technology in human induced pluripotent stem cells (hiPSC) holds tremendous potential for basic research and cell-based gene therapy. However, the fulfillment of these promises relies on the capacity to efficiently deliver exogenous nucleic acids and harness the repair mechanisms induced by the nuclease activity in order to knock-out or repair targeted genes. Moreover, transient delivery should be preferred to avoid persistent nuclease activity and to decrease the risk of off-target events. We recently developed bacteriophage-chimeric retrovirus-like particles that exploit the properties of bacteriophage coat proteins to package exogenous RNA, and the benefits of lentiviral transduction to achieve highly efficient, non-integrative RNA delivery in human cells. Here, we investigated the potential of bacteriophage-chimeric retrovirus-like particles for the non-integrative delivery of RNA molecules in hiPSC for CRISPR/Cas9 applications.

Results: We found that these particles efficiently convey RNA molecules for transient expression in hiPSC, with minimal toxicity and without affecting the cell pluripotency and subsequent differentiation. We then used this system to transiently deliver in a single step the CRISPR-Cas9 components (Cas9 mRNA and sgRNA) to generate gene knockout with high indel rate (up to $85 \%$ ) at multiple loci. Strikingly, when using an allele-specific sgRNA at a locus harboring compound heterozygous mutations, the targeted allele was not altered by NHEJ/MMEJ, but was repaired at high frequency using the homologous wild type allele, i.e., by interallelic gene conversion.
\end{abstract}

\footnotetext{
* Correspondence: john.devos@inserm.fr

'IRMB, Univ Montpellier, INSERM, CHU Montpellier, Hôpital St Eloi, 80 avenue Augustin Fliche, 34295 Montpellier, France

${ }^{6}$ Department of Cell and Tissue Engineering, Univ Montpellier, CHU Montpellier, Montpellier, France

Full list of author information is available at the end of the article
}

C C The Author(s). 2021 Open Access This article is licensed under a Creative Commons Attribution 4.0 International License, which permits use, sharing, adaptation, distribution and reproduction in any medium or format, as long as you give appropriate credit to the original author(s) and the source, provide a link to the Creative Commons licence, and indicate if changes were made. The images or other third party material in this article are included in the article's Creative Commons licence, unless indicated otherwise in a credit line to the material. If material is not included in the article's Creative Commons licence and your intended use is not permitted by statutory regulation or exceeds the permitted use, you will need to obtain permission directly from the copyright holder. To view a copy of this licence, visit http://creativecommons.org/licenses/by/4.0/. The Creative Commons Public Domain Dedication waiver (http://creativecommons.org/publicdomain/zero/1.0/) applies to the data made available in this article, unless otherwise stated in a credit line to the data. 
Conclusions: Our results highlight the potential of bacteriophage-chimeric retrovirus-like particles to efficiently and safely deliver RNA molecules in hiPSC, and describe for the first time genome engineering by gene conversion in hiPSC. Harnessing this DNA repair mechanism could facilitate the therapeutic correction of human genetic disorders in hiPSC.

Keywords: hiPSC, Transduction, CRISPR, Retrovirus-like particles, Gene conversion, Knock-out

\section{Background}

Human pluripotent and induced stem cells (hPSC and hiPSC, respectively) can self-renew, display unlimited proliferative potential, and can differentiate into any cell type of the three germ layers (ectoderm, mesoderm, endoderm). Therefore, they hold tremendous potential not only for basic research and disease modeling, but also for cell production for clinical applications $[1,2]$. This potential has been magnified by the development of gene editing tools, particularly those based on clustered regularly interspaced short palindromic repeats (CRISPR) technologies, to genetically manipulate the hPSC genome [3, 4]. This has allowed the generation of numerous lines with isogenic controls that have become invaluable tools for gene function analysis, genetic disorder modeling, and autologous or allogenic tissue generation for cell-based therapies [1,2].

However, delivering nucleic acids in hPSC for overexpression or genetic engineering is still a challenging task. This can be explained by several factors, including inefficient delivery systems for hPSC, high cell death rates following transfection using standard transfection tools, difficulties to sub-clone these cells, and low tolerance to DNA double-strand breaks (DSB) [4-6]. Despite recent improvements based on new strategies, such as the transfection of ribonucleoprotein complexes, and the development of new gene transfer tools to enhance delivery in hPSC [7-14], new systems are still required to efficiently deliver nucleic acids in hPSC with minimal toxicity.

Particularly, it would be important to develop a system to efficiently deliver RNA molecules for transient overexpression without transgene insertion in the genome. Currently, mRNA molecules can be delivered in hPSC by electroporation and lipofection or via non-viral particles. However, these systems are usually highly toxic and result in low transfection efficacy. Recently, several groups have described non-integrative RNA delivery systems that are based on modified viral particles and that combine the viral vector high transduction efficacy and low toxicity, without genome integration of the viral payload [15-20]. Several of these systems rely on bacteriophage-chimeric retrovirus-like particles to encapsulate concomitantly (but with variable efficiency) different types of RNA molecules, for instance CRISPRassociated protein 9 (Cas9) mRNA and the CRISPRassociated protein 9 (Cas9) necessary for CRISPR/Cas9 gene editing $[21,22]$. Therefore, we asked whether one of these systems could be used to deliver RNA molecules for transient overexpression and genome engineering in hiPSC. To this aim, we targeted three genes [multiciliate differentiation and DNA synthesis associated cell cycle protein (MCIDAS), and coiled-coil domain containing $40(C C D C 40)]$ implicated in the pathogenesis of primary ciliary dyskinesia (PCD), a rare pulmonary genetic disorder, and two genes with therapeutic interest for T-cell engineering [ $\mathrm{T}$ cell receptor alpha constant $(T R A C)$ and C-X-C chemokine receptor type 4 (CXCR4)].

First, we found that bacteriophage-chimeric retroviruslike particles can very efficiently transduce hiPSC lines with minimal toxicity and no impact on pluripotency. Then, we used this system to simultaneously and efficiently transfer sgRNA and Cas9 mRNA for non-homologous end-joining (NHEJ)/micro-homology end-joining (MMEJ)-based gene editing at multiple loci. Finally, we demonstrated for the first time that interallelic gene conversion is a DNA repair mechanism that can be activated in hiPSC following introduction of a DNA DSB. This mechanism was harnessed to correct a heterozygous mutation in a patient hiPSC line and for converting heterozygous mutations into homozygous mutations.

\section{Results}

\section{Bacteriophage-chimeric retrovirus-like (LentiFlash ${ }^{\oplus}$ )} particles for highly efficient and transient RNA delivery in hiPSC

To investigate whether LentiFlash ${ }^{\circ}$ particles can transduce hiPSC, we generated particles containing the fluorescent reporter ZsGreen mRNA (LF-ZsGreen) and used them at three doses $(0.5,2$, and $5 \mathrm{pg}$ p 24/cell) to transduce a hiPSC line (HY03) derived from a healthy individual [23]. Analysis of ZsGreen expression by fluorescence microscopy and flow cytometry at $48 \mathrm{~h}$ post-transduction revealed that more than $97 \%$ of cells were transduced (all three tested doses) and that fluorescence signal intensity was dosedependent $(n=3)$ (Fig. 1a-c). Moreover, cell counting and lactate dehydrogenase (LDH; a marker of cytotoxicity) quantification in supernatant confirmed the low toxicity observed by optical microscopy, without significant increase in LDH concentration or cell loss after transduction with particles at the concentration of 0.5 and $2 \mathrm{pg}$ p24/ cell. We observed only a slight increase in LDH concentration at the highest dose tested (5 pg p24/cell), without any effect on cell proliferation (Fig. 1d, e). ZsGreen 


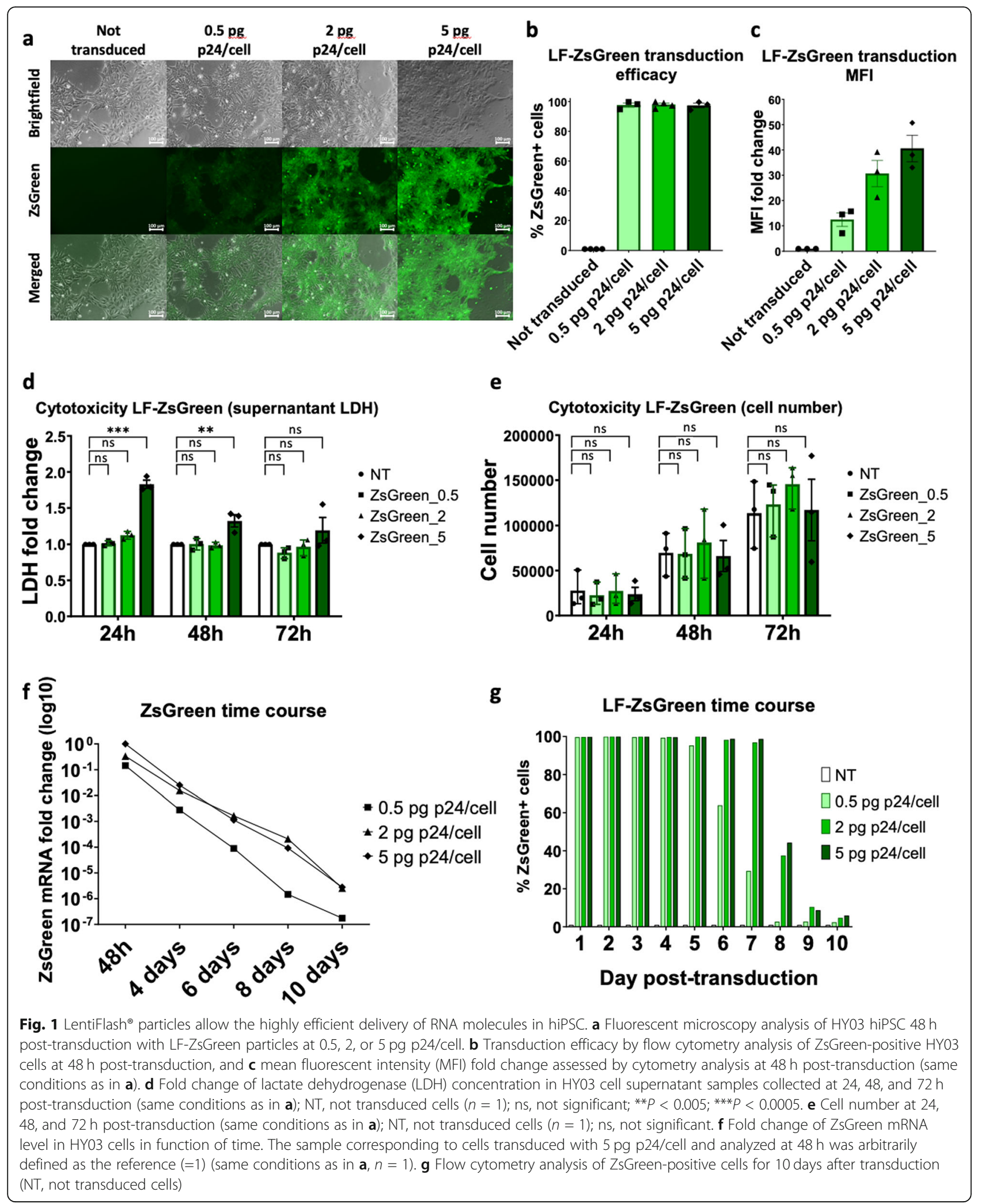

expression monitoring by real-time quantitative PCR (qPCR) and flow cytometry analysis for 10 days revealed the transient nature of the system with a sharp decline in
ZsGreen mRNA level over time, followed by a progressive decrease in ZsGreen protein expression (Fig. 1f, g). This decrease was dose-dependent and reached control levels 
at day 10. The percentage of ZsGreen-positive cells peaked at $24 \mathrm{~h}$ post-transduction (all three doses), whereas the fluorescence signal intensity reached its maximum at $48 \mathrm{~h}$ (Fig. $1 \mathrm{~g}$, and Fig. S1a-b). These findings confirmed previous data obtained in HeLa cells (data not shown) and clearly show that we can specifically quantify ZsGreen RNA (by qPCR) and ZsGreen protein expression (by cytometry) in cells transduced with LentiFlash ${ }^{\circ}$ particles. The detection of ZsGreen RNA demonstrates that the RNA contained in the LentiFlash ${ }^{\circ}$ particles was efficiently transferred in the transduced cells. These experiments also showed that while ZsGreen RNA expression decreased already at $48 \mathrm{~h}$ after transduction, ZsGreen protein levels remained high for 5-10 days (in function of the used dose) because the protein half-life is quite long. These results suggest that after transduction of LentiFlash particles, protein expression in target cells is correlated with the RNA delivery. Transduced hiPSC retained a pluripotent morphology and expressed pluripotency markers, as indicated by the expression of NANOG, OCT3/4, SOX2, and SSEA4 (Fig. S1c). Pluripotency was confirmed by differentiating transduced cells into definitive endoderm that expressed CXCR4, FOXA2, and SOX17 (Fig. S1d). We replicated these results in two additional hiPSC lines, one derived from a patient with PCD (PCD_02:30 line) [24] and the other from a patient with chronic obstructive pulmonary disease (COPD) (iCOPD9_B27 line) (Fig. S2).

\section{Efficient CRISPR/Cas9-mediated NHEJ/MMEJ genome editing in hiPSC}

Then, we asked whether LentiFlash ${ }^{\bullet}$ particles could be used to transiently deliver CRISPR/Cas9 reagents in hiPSC for genome engineering. To this aim, we first generated a non-clonal GFP-reporter stable cell line (HY03GFP) by transducing HY03 cells with integrative recombinant lentiviral particles (ILV-EF1-GFP) (Fig. S3). Then, we transduced HY03-GFP cells with LentiFlash ${ }^{\oplus}$ particles that carry a sgRNA targeting the GFP sequence and the Cas9 mRNA (LF-CRISPR/Cas9-GFP) at three doses (0.5, 2 , and $5 \mathrm{pg}$ p24/cell) to assess NHEJ/MMEJ-mediated GFP knock-out. Six days post-transduction, fluorescent microscopy and flow cytometry analysis showed that GFP expression was absent in more than $90 \%$ of cells at the highest dose tested (Fig. 2a, b). Sanger sequencing and Interference of CRISPR Edits (ICE) analysis confirmed the high frequency of NHEJ/MMEJ mutations at the targeted GFP sequence (Fig. 2c).

Then, we generated four additional LentiFlash ${ }^{\bullet}$ vectors (LF-CRISPR/Cas9-MCIDAS, LF-CRISPR/Cas9-DNAH5, LF-CRISPR/Cas9-TRAC, and LF-CRISPR/Cas9-CXCR4) to target two endogenous genes involved in motile ciliary biology (MCIDAS and DNAH5) and two endogenous genes implicated in T-cell biology (TRAC and CXCR4). Transduction of HY03 hiPSC with increasing doses resulted in dose-dependent NHEJ/MMEJ-mediated mutagenesis at all four loci, as indicated by Sanger sequencing and ICE analysis. The indel rates obtained were gene-dependent, with mutagenesis rates of 86,36 , 40, and 28\% for MCIDAS, DNAH5, TRAC, and CXCR4, respectively (Fig. 2c). For DNAH5, in line with the ICE analysis, NGS-based amplicon sequencing showed that $49.5 \%$ of reads displayed deletions, confirming a high efficiency of CRISPR/Cas9 editing (Fig. S4). As seen for ZsGreen expression, Cas9 mRNA level monitoring by real-time qPCR for 7 days confirmed the rapid mRNA decline after LF-CRISPR/Cas9-MCIDAS (0.5 pg p24/cell) or LF-CRISPR/Cas9-CXCR4 (7.5 pg p24/cell) transduction (Fig. 2d). This is particularly interesting for limiting Cas9 activity over time and reducing potential off-target mutations. To demonstrate that Cas9 mRNA and sgRNA are co-packaged in LentiFlash ${ }^{\circ}$ particles, we assessed CRISPR/Cas9 targeting efficiency using various batches of LentiFlash ${ }^{\circ}$ particles to edit the GFP gene in a clonal HCT116 cell line that contains one copy of GFP per cell. Specifically, we analyzed GFP expression at day 7 after transduction of LentiFlash ${ }^{\bullet}$ particles that express (i) Cas9-MS2 alone, (ii) sgRNAGFP-PP7 and Cas9 without the MS2 aptamers (two different plasmids), (iii) sgRNAGFP-PP7 and Cas9-MS2 (two different plasmids), and (iv) sgRNAGFP-PP7 and Cas9-MS2 (both in the same expression plasmid, which corresponds to the LentiFlash $^{\bullet}$ generation process used for the iPSC experiments described in this article). We observed $75 \%$ of GFP editing when cells were transduced with sgRNAGFP-PP7 or Cas9 without the MS2 aptamers. This indicated that some Cas9 proteins are passively packaged or embedded with the guide packaging. When Cas9 RNA is actively packaged, the editing efficiency increased to more than 90\% (supplementary Fig. S5). As expected, we obtained the best editing efficiency (97.7\%) using LentiFlash ${ }^{\circ}$ particles produced with a single expression plasmid that allows the active packaging of sgRNA-PP7 and Cas9-MS2. These data show that although the Cas9 protein is passively packaged during the production process, the CRISPR/Cas9 system is more efficient when Cas9 is actively packaged thanks to the presence of MS2 aptamers.

Sub-cloning of cells transduced with $0.5 \mathrm{pg}$ p24/cell LF-CRISPR/Cas9-DNAH5 or LF-CRISPR/Cas9-MCID AS particles and screening by high-resolution melting analysis (HRMA) confirmed gene editing, with $78 \%$ and $82 \%$ of clones mutated at the DNAH5 and MCIDAS locus, respectively (Fig. 2e). Sanger sequencing of DNAH5 and MCIDAS in 11 and 20 randomly selected mutant clones (according to the HRMA results) confirmed the targeted mutagenesis (Fig. 2f). Furthermore, the characterization of two knock-out cell lines (one for $D N A H 5$ and one for MCIDAS) confirmed the expression 





of pluripotency markers (NANOG, OCT3/4, SOX2, and SSEA4), the absence of the most recurrent genomic abnormalities found in hiPSC, and the absence of Cas9 genomic integration (Fig. S6).

Finally, to confirm the data reproducibility, we performed CRISPR/Cas9 editing in the other two hiPSC lines (PCD_02:30 and iCODP9_B27) using optimized particle concentrations. This resulted in comparable mutagenesis rates in all cell lines for the four targeted genes (Fig. S7).

\section{Allele-specific gene editing induces interallelic gene conversion in hiPSC}

The PCD_02:30 hiPSC line was derived from a patient with PCD harboring $C C D C 40$ compound heterozygous mutations [24]. The two heterozygous pathogenic variants correspond to a 2-nucleotide frameshift deletion in exon $7(\Delta-2 n$ t, allele 1$)$ and a single nucleotide polymorphism in the splice site acceptor of exon 19 (G > A, allele 2). To investigate whether a CRISPR/Cas9 reframing approach could restore the reading frame in allele 1 , we designed an allele-specific sgRNA that encompasses in its seed region the $\Delta-2$ nt variant (Fig. 3a). We then used this sgRNA to generate the corresponding LentiFlash $^{\circ}$ particles (LF-CRISPR/Cas9-CCDC40-YGT). Transduction of the PCD_02:30 hiPSC line did not lead to the generation of indels at the targeted locus, but decreased the percentage of $\Delta-2$ nt alleles and increased the percentage of wild type allele (WT) at this position, as indicated by Sanger sequencing and ICE analysis (Fig. $3 b)$. These results were reproducible $(n=3)$ and dosedependent, with an increase of the WT allele percentage from $50 \%$ (heterozygous state) to $90 \%$ after transduction with LF-CRISPR/Cas9-CCDC40-YGT particles at $5 \mathrm{pg}$ p24/cell. To determine whether these results were due to larger deletions of the targeted $\Delta-2$ nt allele with a resulting over-representation of the WT sequence, we counted the copies of the WT allele by droplet digital PCR (ddPCR). In agreement with the Sanger sequencing data, the WT allele copy number was increased in a dose-dependent manner $(n=3)$, with a mean copy number of 1.43 (equivalent to $71 \%$ of WT alleles compared with $90 \%$ by ICE analysis) for the $5 \mathrm{pg}$ p24/cell condition (Fig. 3b). This confirmed that the targeted $\Delta-2 n$ t allele was corrected to a WT allele. To confirm that our sgRNA design was allele-specific, we transduced the HY03 hiPSC line (WT at the CCDC40 locus) with LFCRISPR/Cas9-CCDC40-YGT particles at $5 \mathrm{pg}$ p24/cell. We did not detect any indel by Sanger sequencing, confirming the sgRNA specificity (data not shown). This finding was not specific to the use of the LentiFlash ${ }^{\circ}$ system because we obtained interallelic gene conversion also by electroporating the PCD_02:30 iPSC line with CRISPR/Cas9 RNPs targeting the $\Delta$-2nt allele, albeit at a lower efficiency (interallelic gene conversion occurring, on average, in $42 \%$ of cells) (Fig. S8a). Of note, the electroporation conditions must be optimized for each cell line. Indeed, the conditions used to electroporate PCD 02:30 iPSC resulted in complete loss of HY03 hiPSC viability (data not shown). Therefore, we concluded that allele-specific targeting of the $\Delta$-2nt pathogenic variant resulted in DNA repair mediated by interallelic gene conversion.

To determine whether this phenomenon was conserved upon loss of pluripotency, we differentiated PCD_02:30 hiPSC into neural progenitors (Fig. S8b). Transduction of these progenitors with LF-CRISPR/ Cas9-CCDC40-YGT at $0.5,2$, and $5 \mathrm{pg}$ p24/cell gave similar results as those obtained with the parental hiPSC line: increase of the WT allele percentage from 50 (heterozygous state) to $90 \%$ after transduction at the highest dose. This suggests that interallelic gene conversion occurs also after hPSC differentiation and loss of pluripotency (Fig. S8c).

Finally, to determine whether interallelic gene conversion could occur at another locus and more generally whether this genome engineering approaches could be harnessed to convert heterozygous mutations to homozygous mutations, we derived three heterozygous clonal lines with a frameshift mutation in DNAH5 (DNAH5 A6, DNAH5_C3, and DNAH5_B5; Fig. S9). These clones were obtained by transducing the HY03 hiPSC line with LF-CRISPR/Cas9-DNAH5 (see above), and harbored one allele with an indel $(7 \mathrm{nt}$ deletion $[\Delta-7 \mathrm{nt}], 1 \mathrm{nt}$ insertion $[\Delta+1 \mathrm{nt}]$, or a combination of $1 \mathrm{nt}$ deletion with $2 \mathrm{nt}$ insertion $[\Delta-1 /+2 n t]$ for DNAH5_A6, DNAH5_C3, and DNAH5_B5, respectively) that disrupted the sgRNA binding site, and a WT allele that could be targeted to introduce a DSB. Transduction with LF-CRISPR/Cas9DNAH5 at the optimized dose of $0.5 \mathrm{pg}$ p24/cell showed the absence of off-target mutations at sites containing up to three mismatches and the absence of the most recurrent genomic abnormalities found in hiPSC (Fig. S9). It also resulted in gene conversion with an increase of the mutant allele copy number specific to each clone (the $\Delta-7 \mathrm{nt}$ for DNAH5_A6, $\Delta+1 \mathrm{nt}$ for DNAH5_C3 and $\Delta-1 /+2$ nt for DNAH5_B5), as indicated by Sanger sequencing and ICE analysis (Fig. S10). These results confirmed that allele-specific targeting in hiPSC results in DNA repair mediated by interallelic gene conversion.

\section{Discussion}

Our data show that LentiFlash ${ }^{\bullet}$ particles very efficiently deliver non-integrative RNA molecules in hiPSC. We demonstrated that this system can be used to transiently express RNA molecules in up to $97 \%$ of transduced cells. Moreover, this highly efficient transduction system does not cause marked cytotoxicity 


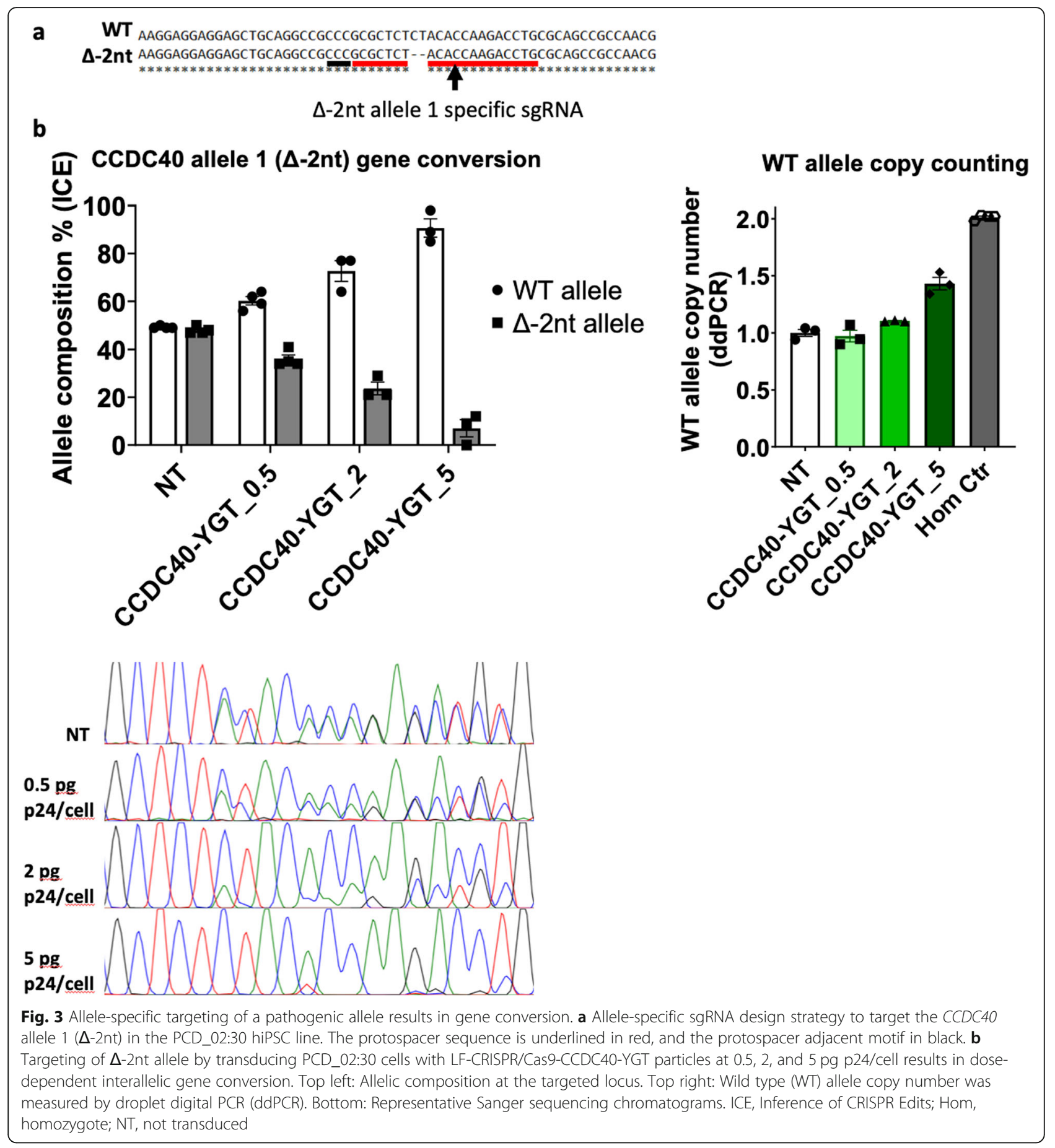

and thus allows reducing the number of cells to be used and performing experiments directly after transduction, without the need of an extended recovery period. This could be particularly interesting for many applications, including the expression of selected transcription factors to direct hPSC differentiation.

Furthermore, thanks to its versatility, this system can be used to deliver simultaneously various RNA types, including the Cas9 mRNA and sgRNA for CRISPR/ Cas9-based gene editing. Our result shows that the LentiFlash ${ }^{\circ}$ technology allows packaging both the Cas9 RNA and the Cas 9 protein, especially because the corresponding encoding DNA is efficiently transfected in the producer cells. The editing rates we obtained in HCT116 cells that contain one copy of the target gene per cell cannot be extrapolated to the level of expression of 
endogenous genes where many factors can interfere with the editing efficiency (gene copy number, availability of the gene within chromatin, sgRNA design). In fact, a small amount of Cas9 protein might efficiently edit a gene present as a single copy per cell, but be ineffective in other gene configurations [25]. We demonstrated that LentiFlash ${ }^{\circ}$ particles can be exploited to efficiently manipulate the hiPSC genome via the NHEJ/MMEJ repair pathways. By targeting five genes in three different hiPSC lines, we could generate indels in up to $85 \%$ of the targeted alleles. Moreover, we did not observe offtarget events at any of the loci analyzed in the five stable cell lines generated in this study.

Thanks to the use of the active cellular entrance pathway of classical lentiviral vectors, LentiFlash ${ }^{\circ}$ delivery does not disrupt cell integrity, differently from other transfection systems, such as electroporation and lipofection. This results in very low cell toxicity and minimal cell death after transduction (Fig. 1d, e). This easy-touse technology is also very efficient ( $>97 \%$ of cells expressed the transgene of interest) (Fig. 1), thus saving time and work linked to cell selection or sorting. Recent studies showed that lentivirus-like particles (LVLP) can be generated with an approach similar to the one described in the present work to obtain a CRISPR/Cas9 system using saCas9, SpCas9, or adenine-based editing systems $[15,26,27]$. The design of these LVLP (number and location of the MS2 coat protein, number of MS2 aptamer repeats, and 3'UTR modification) was different from ours. Like these authors, we observed that LentiFlash $^{\circ}$ particles were morphologically similar to conventional lentiviral vectors [20]. Differently from us, these authors reported that the viral titers were decreased when MCP was cloned into the matrix gene. Indeed, the titers we obtained with these vector batches remained high, and they are in the best design configuration for efficient gene editing. Other groups used similar bacteriophage systems to create particles that can transfer RNA into target cells using a slightly different design compared with ours $[15,18,19]$. Briefly, Knopp et al. replaced the nucleocapsid by a genetically fused MS2 heterodimer to generate non-integrating gammaretroviral murine leukemia virus-based CRISPR/Cas9 all-in-one particles. Lindel et al. used a transient prototype foamy virus (PFV) vector system to deliver Cas9 mRNA combined with an integration-deficient retroviral vector (IDRV) to carry the sgRNA, allowing efficient gene editing. They also showed that sgRNA delivery using the transient PFV vector was less efficient than with the IDRV vector, but resulted in significant editing rates when transduced $24 \mathrm{~h}$ after the Cas9 mRNA-carrying transient PFV. Although LentiFlash ${ }^{\circ}$ particles contain RNPs, sgRNA and RNA for Cas9 are actively encapsidated via the MS2 coat protein-aptamer interaction. We think that some editing activity can be attributed to passively packaged or embedded Cas9 protein and that this activity might be maintained by the expression of Cas9 RNA. This might explain the increased editing efficiency when using the active packaging system. LentiFlash ${ }^{\bullet}$ particles allow the delivery of RNA molecules in the cell cytoplasm, without any viral sequence, thus completely avoiding reverse transcription and integration in the cell genome (Fig. S6e). Therefore, LentiFlash particles could be an interesting tool for transient expression for gene overexpression, gene editing, or transcription factorbased differentiation.

Considering the high capacity of LentiFlash ${ }^{\circ}$ particles to efficiently deliver CRISPR/Cas9 reagents at multiple loci, we investigated whether this system could be used in a reframing strategy at a pathogenic locus. Therefore, we designed a sgRNA specific for a pathogenic variant in a patient-derived hiPSC line, to introduce indels in the close vicinity of this frameshift mutation. To our surprise, this did not result in the generation of indels, but in interallelic gene conversion that allowed correcting the variant to a WT sequence in more than $40 \%$ of transduced cells. Interestingly, this phenomenon was conserved following hiPSC differentiation to neural progenitors, suggesting that it is not restricted to pluripotent cells. Furthermore, we confirmed gene conversion after allele-specific targeting of a frameshift mutation at an additional locus (DNAH5) in three clones derived from a second hiPSC line (HY03). To the best of our knowledge, interallelic gene conversion has never been described in hPSC.

Gene conversion is a form of homologous recombination that is initiated by DNA DSB and results in the unidirectional transfer of genetic material from the intact homologous sequence to the region that contains the DSB. This phenomenon is well documented during meiosis and is a recognized driver not only of human genome evolution, but also of inherited diseases. However, it is also involved in the occasional phenotype reversion of genetic diseases, such as epidermolysis bullosa [28]. More recently, this DNA repair mechanism was described in other cell types after CRISPR/Cas9-mediated DNA DSB. One report demonstrated interallelic gene conversion in cultured human cells, including human embryonic kidney cells (HEK293T) and human primary lung stromal cells [29], but only in $2.3 \%$ and $0.15 \%$ of the alleles, respectively. Two other reports described interallelic gene conversion in mouse embryonic stem cells, with different yields: $4 \times 10^{-5}$ in the study by Susani et al. [30] and $40 \%$ in the study by Wu et al. [31]. As we did in our study, Wu et al. used an allele-specific sgRNA that included the variant sequence in the protospacer adjacent motif. Finally, several articles described this phenomenon after CRISPR/Cas9 injection in early 
embryos. Although interallelic gene conversion in embryos has been controversial [32-35], this DNA repair mechanism has been shown to be activated in mouse [31], rat [36], and human embryos [37-39]. Although the embryo number and targeted loci remain low, interallelic gene conversion following CRISPR/Cas9 mutagenesis seems to occur more frequently in embryos: $28 \%$ in the rat (2/7 embryos) [36], $18 \%$ in the mouse (4/22 embryos) [31], and up to $40 \%$ in human embryos [37, 38]. Moreover, this DNA repair pathway can be modulated through the use of exogenous molecules. For instance, the 53BP1 inhibitor i53 increases gene conversion in different human and mouse cell lines [40]. Moreover, RAD51 was recently used to increase interallelic gene conversion in mouse embryos from 26 to $74 \%$ by Wilde et al. [41]. These studies indicate that interallelic gene conversion might be a conserved DNA repair mechanism activated at high frequency during early mammalian embryogenesis and consequently also in pluripotent stem cells. As DNA damage response can be cell-type specific [42], and the DNA repair response is more efficient in pluripotent stem cells than in somatic cells [43, 44], we investigated whether interallelic gene conversion is also active beyond the pluripotency stage. We obtained similar results in neural progenitors derived from the same hPSC line, suggesting that this phenomenon is at least conserved in some cell types.

\section{Conclusions}

Our data show, for the first time, the occurrence of interallelic gene conversion in hiPSC after CRISPR/Cas9 induced DSB. This repair process is observed at a high rate only when one allele is specifically targeted. Interallelic gene conversion in hiPSC could be used to efficiently engineer their genome without donor DNA template. Moreover, unraveling the molecular machinery responsible for gene conversion in hiPSC could lead to the development of strategies to modulate and increase this DNA repair pathway in differentiated cells. This could provide a simple way to convert heterozygote alleles to a homozygous state at targeted loci, opening the way to correct human recessive genetic disorders caused by compound heterozygous mutations and human autosomal dominant genetic disorders.

\section{Methods}

\section{hiPSC lines, culture, and passaging}

Three hiPSC lines reprogrammed in the laboratory were used: (i) HY03 (alternative name listed in the hPSCReg registry: UHOMi002-A), derived from an healthy individual [23]; (ii) PCD_02:30 (alternative name listed in the hPSCReg registry: UHOMi001-A), derived from a patient with primary ciliary dyskinesia harboring compound heterozygous mutations in the $C C D C 40$ gene [24]; and (iii) iCOPD9_B27, derived from a patient with chronic obstructive pulmonary disease (COPD) [45]. The three hiPSC lines were maintained in undifferentiated state in feeder-free conditions on growth factorreduced Geltrex matrix (Thermo Fisher Scientific) in Essential $8^{\text {ma }}$ (E8) medium (Thermo Fisher Scientific) at $37{ }^{\circ} \mathrm{C}$ in a humidified atmosphere of $5 \% \mathrm{CO}_{2}$ in air. Cells were dissociated using Versene (Thermo Fisher Scientific) for single-cell passaging every $4-5$ days (when cells reached $70-80 \%$ confluence) followed by plating (1:10 to 1:20 ratio) with $10 \mu \mathrm{M}$ of the ROCK inhibitor Y-27632 (Tocris). The E8 medium was changed daily.

\section{sgRNA design and selection}

DNAH5 and MCIDAS sgRNAs were selected to target a sequence in an exon shared by all the gene transcripts and to be as specific as possible using the freely available CRISPOR online tool (http://crispor.tefor.net/) [46]. For the CCDC40 reframing/gene conversion experiment, the sgRNA was selected using CRISPOR online tool in order to include the " $\Delta-2 \mathrm{nt}$, allele 1" mutation [c.1116_1117delCT, p.Y378Hfs] and to produce a DNA DSB as close as possible to the mutation. The sgRNAs targeting TRAC, CXCR4, and GFP were previously described [47-49]. The sgRNA sequences are listed in Supplementary Table S1.

\section{Integrative lentiviral vector particle production, purification, and quantification by quantitative PCR}

Three plasmids were used to produce the recombinant lentiviral particles ILV-EF1-GFP. A first plasmid pLVGagPol (wt) provided a nucleic acid encoding viral gag and pol genes lacking vif, vpr, vpu, and nef genes. A second plasmid pVSVG provided a nucleic acid encoding the vesicular stomatitis virus envelope glycoprotein (VSV-G). A third self-inactivating expression plasmid encoded the GFP fluorescent reporter under the control of the human elongation factor 1 alpha promoter (EF1a) (Fig. S11). Viral particles were produced in a 10-layer CellSTACK chamber $\left(6360 \mathrm{~cm}^{2}\right.$, Corning) after transfection of the three plasmids in HEK293T cells using the standard calcium phosphate procedure. Twenty-four hours post-transfection, the supernatant was discarded and replaced by fresh medium and cells were incubated at $37^{\circ} \mathrm{C}$ in a humidified atmosphere of $5 \% \mathrm{CO}_{2}$ in air. After medium change, supernatant was collected, clarified by centrifugation at $3000 \mathrm{~g}$ for $5 \mathrm{~min}$, and microfiltered through $0.45-\mu \mathrm{m}$ pore size sterile filter units (Stericup, Millipore). Supernatant was harvested several times, and finally, all samples were pooled (crude harvest). The crude harvest was concentrated and purified by ultrafiltration and diafiltration.

Transduction unit (TU) titration assays of the pooled supernatants were performed as follows. HCT116 cells 
were seeded in 96-well plates. Twenty-four hours later, transduction was performed using pooled supernatants and the rLV-EF1-GFP internal standard (six serial dilutions). Three days post-transduction, cells were trypsinized and the titer $(\mathrm{TU} / \mathrm{ml})$ was determined by qPCR after extraction of genomic DNA using the Nucleospin tissue gDNA extraction kit (Macherey-Nagel). The titer determined by qPCR and expressed in $\mathrm{TU} / \mathrm{ml}$ was normalized to the internal standard, the titer of which was previously determined by FACS.

MS2 and PP7-chimeric retrovirus-like particle (LentiFlash ${ }^{\circledast}$ ) production, purification, and quantitation by p24 ELISA assay

The non-integrative LentiFlash ${ }^{\circ}$ particles (Flash Therapeutics) that exploit the bacteriophage MS2 or PP7-Coat and its cognate RNA aptamer were previously described by Prel et al. [20]. Like for the integrative lentiviral particles, three plasmids were used to produce recombinant LentiFlash $^{\circ}$ particles in HEK293T cells: (i) the pLVGagPol plasmid encoding the viral gag and pol genes modified to harbor the MS2 and/or PP7-Coat within the gag gene and referred to as pLF-GagPol ZF_PCP and pLF-GagPol MA_MCP.ZF_PCP. pLF-GagPol ZF_PCP was generated using the p8.74 $\triangle \mathrm{ZF}$ MS2Coat construct, described by Prel et al. [20], by replacing the MS2 coat protein sequence with the capsid assembly-deficient PP7 coat protein PP7 $\triangle \mathrm{FG}$ sequence described by Chao et al. [50]. The human codon-optimized PP7 $\triangle \mathrm{FG}$ coding sequence was synthesized by Geneart (Thermo Fisher Scientific) and cloned, using the In-Fusion ${ }^{\circ}$ cloning kit (Takara Bio), into p8.74 $\triangle$ ZF_MS2Coat previously digested with HpaI. pLF-GagPol MA_MCP.ZF_PCP was generated by inserting the MS2 coat protein coding sequence into the pLF-GagPol ZF_PCP plasmid between the codons corresponding to the 127th and 128th amino acid of the MA protein using the In-Fusion ${ }^{\circ}$ cloning kit (Takara Bio) after PCR amplification of the two fragments; (ii) the pVSVG plasmid encoding the VSV-G glycoprotein; and (iii) the plasmid encoding the RNA cargo, flanked by the bacteriophage aptamers to enable RNA mobilization into lentiviral particles through the interaction with the corresponding coat protein cloned in the Gag sequence. For the ZsGreen reporter, the ZsGreen mRNA was flanked by PP7 aptamers on the RNA transfer plasmid as shown in supplementary Fig. S11, and the pLF-GagPol ZF_PCP was used for transfection of the produced cells. For the CRISPR/Cas9 system, PP7 aptamers were inserted into the tetraloop and stemloop 2 of the sgRNA scaffold, the Cas9 nuclease mRNA sequence was flanked by MS2 aptamers on the RNA transfer plasmid, as detailed in supplementary Fig. S11, and the pLF-GagPol MA_MCP.ZF_PCP packaging plasmid was used for transfection. All newly generated constructs were verified by restriction enzyme digestion and sequencing. The primer sequences and additional details are available upon request. Production, concentration, and purification of LentiFlash ${ }^{\circ}$ particles were done as described for the integrative viral particles.

The functionality of LentiFlash ${ }^{\bullet}$ particles carrying multiple RNA molecules encapsidated using a bacteriophage chimeric system, regardless of the position of the bacteriophage coat protein in the gag gene, was demonstrated and patented in 2015 [51]. We evaluated various designs to determine the best localization of the MS2 coat protein in the gag gene. We found that the maximum amount of RNAs is packaged into LentiFlash particles when the MCP is inserted in the matrix gene. We did not observe any significant decrease of the p24 titers of LentiFlash ${ }^{\circ}$ batches containing the MCP inserted into MA compared with constructs in which the MCP was inserted in the NC. The p24 titers of these batches remained high, and these particles effectively led to high and rapid level of expression of the gene of interest. Following the first LentiFlash ${ }^{\circ}$ patent, the functionality of LentiFlash ${ }^{\circ}$ particles to transfer the CRISPR/Cas9 system was then demonstrated and patented in 2016 [52]. We performed many additional experiments with this MCP-MA/PCP-NC optimized helper plasmid to confirm the best editing efficiency of these particles in different cell types and/or by targeting various genes.

For quantification, the p24 core antigen was detected directly in the viral supernatant with a HIV-1 p24 ELISA kit (Perkin Elmer), as specified by the supplier. The viral titer (expressed in physical particles per $\mathrm{ml}$ ) was calculated from the p24 amount, knowing that $1 \mathrm{pg}$ of p24 corresponds to $10^{4}$ physical particles.

\section{hiPSC transduction}

The day before transduction, hiPSC were plated as single cells $\left(25000 \mathrm{cells} / \mathrm{cm}^{2}\right)$ in $24-$ or 48 -well plates coated with Geltrex matrix in E8 medium supplemented with $10 \mu \mathrm{M}$ of Y-27632. Two hours before transduction, the medium was changed with fresh E8 supplemented with $10 \mu \mathrm{M}$ Y-27632. Transduction was performed using integrative lentiviral particles or LentiFlash particles in E8 medium supplemented with $10 \mu \mathrm{M} \mathrm{Y}-27632$ and $8 \mu \mathrm{g} / \mathrm{ml}$ polybrene (Sigma Aldrich) for 16 to $18 \mathrm{~h}$ before changing the medium.

\section{Electroporation}

For electroporation, $4 \times 10^{5}$ PCD_02:30 iPSC were transfected with 52 pmol Cas 9 protein and 60 pmol premixed Alt-R CRISPR-Cas 9 tracrRNA and Alt-R CRISPR-Cas9 crRNA (IDT DNA Technologies) in Nucleofector Solution SF (Lonza) in a final volume of $25 \mu$ l. Cells were transfected with the Amaxa 4D-Nucleofector (Lonza) device using program CA-137 and then resuspended in 
with E8 medium supplemented with $10 \mu \mathrm{M}$ Y-27632 for $24 \mathrm{~h}$.

\section{Sanger sequencing and ICE analysis}

Targeted loci were amplified using the appropriate primers (listed in Supplementary Table S2) and the One$\mathrm{Taq}^{\circ}$ DNA Polymerase (NEB) following the manufacturer's instruction. After amplification confirmation by electrophoresis of an aliquot on 2\% agarose gels, PCR products were purified using the QIAquick PCR Purification Kit (QIAGEN), as recommended by the manufacturer. Purified PCR products were analyzed by Sanger sequencing (Eurofins Genomics). Chromatograms were analyzed with the freely available FinchTV version 1.4.0 (Geospiza) and ICE (Synthego) tools [53].

\section{On-target next-generation amplicon sequencing}

Genomic DNA was used as input for PCR (primers described in Table S2) using OneTaq polymerase (New England Biolabs). PCR product was purified using the QIAquick Gel Extraction Kit (Qiagen) according to the manufacturer's instructions and subjected to paired-end read sequencing on an Illumina flow cell MiniSeq MidOutput at Montpellier GenomiX. Genomic PhiX DNA was spiked-in to increase base diversity. Fastq files were analyzed using the CRISPResso2 software with default settings [54].

\section{Clonal line derivation and validation}

Clonal hiPSC lines were obtained by plating transduced cells at low density in 6-well plates coated with Geltrex matrix (from 500 to 10000 cells/well) in E8 medium supplemented with $10 \mu \mathrm{M}$ Y-27632. The medium was changed every day and Y-27632 was added for the first 2 days. After 6-10 days, clones were manually picked and transferred to a well of a 96-well plate coated with Geltrex matrix in E8 medium. Clones were amplified in E8 medium for 5 to 8 days and passaged as small clumps in two wells of 96-well plates (duplicate). One plate was kept in culture and the second was used for screening.

Screening was performed by extracting DNA with the DNA Extract All Reagents Kit (Thermo Fisher Scientific) or the QIAamp DNA Blood Mini Kit (QIAGEN) followed by HRMA using the LightCycler ${ }^{\circ} 480$ SYBR Green kit (Roche) and a standard qPCR program $\left(95^{\circ} \mathrm{C}\right.$ for $10 \mathrm{~min}$, followed by 40 cycles of $95^{\circ} \mathrm{C}$ for $10 \mathrm{~s}, 60^{\circ} \mathrm{C}$ for $15 \mathrm{~s}$, and $72^{\circ} \mathrm{C}$ for $15 \mathrm{~s}$, with a final melting curve including a step of $95^{\circ} \mathrm{C}$ for $5 \mathrm{~s}$ followed by an increase from 65 to $97^{\circ} \mathrm{C}$ with a temperature ramping set to $0.11^{\circ} \mathrm{C} / \mathrm{s}$ ) on a LightCycler 480 (Roche). The identified mutant clones were confirmed by Sanger sequencing as described above.

Newly established clonal lines were validated by (1) Sanger sequencing analysis of off-target sites containing up to three mismatches (primers are listed in Supplementary Table S2), (2) immunofluorescence analysis of OCT3/4, NANOG, SOX2, and SSEA4 expression (pluripotency markers) (antibodies are listed in Supplementary Table S3), and (3) genomic integrity analysis by ddPCR of the copy number variations of the 24 more frequent recurrent genetic abnormalities that cover more than $90 \%$ of all recurrent genetic abnormalities found in hPSC (provided as a service by Stem Genomics) [55].

\section{Copy number variation analysis by droplet digital PCR (ddPCR)}

Copy number variation was evaluated in a duplex reaction in which the target gene (GFP or CCDC40YGT) is amplified using a FAM-labeled probe (IDT DNA Technologies) and the reference gene RPP30 with a HEX-labeled probe (IDT DNA Technologies), set at two copies. Reaction mixes contained $150 \mathrm{ng}$ of purified genomic DNA, 1x ddPCR Supermix (Bio-Rad), $900 \mathrm{nM}$ of each primer (two primers per assay), and $250 \mathrm{nM}$ of each probe (sequences detail can be found in Supplementary Table S2). Reaction mixes were loaded into DG8 cartridges with $70 \mu \mathrm{l}$ of droplet oil (Bio-Rad) per sample and the droplets generated using the QX200 Droplet Generator (Bio-Rad), according to the manufacturer's instructions. Emulsions were transferred to a 96well plate, and samples were amplified in a thermocycler $\left(95^{\circ} \mathrm{C}\right.$ for $10 \mathrm{~min}$, followed by 45 cycles of $95^{\circ} \mathrm{C}$ for $30 \mathrm{~s}$ and $60^{\circ} \mathrm{C}$ for $60 \mathrm{~s}$, with a final elongation step of $98^{\circ} \mathrm{C}$ for $10 \mathrm{~min}$ with temperature ramping set at $2^{\circ} \mathrm{C} / \mathrm{s}$ ). The plate was then loaded on the QX200 Droplet Reader (Bio-Rad), and copy number was determined with the QuantaSoft software.

\section{Gene expression analysis by real-time quantitative PCR}

For qPCR experiments, total RNA was extracted from cells using the RNeasy ${ }^{\circ}$ Mini kit (QIAGEN) following the manufacturer's instructions. Reverse transcription to complementary DNA (cDNA) was performed using the SuperScript $^{\text {tm }}$ First-Strand Synthesis System for RT-PCR (Invitrogen) following the manufacturer's instructions. qPCR was performed using LightCycler 480 SYBR Green I Master (Roche) in 384 plates, in $10 \mu \mathrm{l}$ reactions, including 1x SYBR Green I Master, $0.5 \mu \mathrm{M}$ of each primer, and the cDNA. All reactions were performed in triplicate. A negative control (RNAse/DNAse-free water) was included in each run. The qPCR assays were performed on a LightCycler 480 (Roche) using the following program: $95^{\circ} \mathrm{C}$ for $10 \mathrm{~min}$, followed by 40 cycles of $95^{\circ} \mathrm{C}$ for $10 \mathrm{~s}, 60^{\circ} \mathrm{C}$ for $15 \mathrm{~s}$, and $72{ }^{\circ} \mathrm{C}$ for $15 \mathrm{~s}$, with a final melting curve including a step of $95^{\circ} \mathrm{C}$ for $5 \mathrm{~s}$ followed by an increase from 65 to $97^{\circ} \mathrm{C}$ with a temperature ramping set to $0.11^{\circ} \mathrm{C} / \mathrm{s}$. 
Raw data ( $\mathrm{Ct}$ values) were analyzed using the comparative $\mathrm{Ct}$ method. Gene expression data were calculated as relative to the expression of the GAPDH housekeeping gene. The comparative threshold cycle method $(\Delta \Delta C T)$ was used to quantify relative gene expression, and the obtained quantification was transformed to $2^{-\Delta \Delta C T}$ values.

\section{Immunofluorescence}

Cells were fixed in $4 \%$ paraformaldehyde at room temperature (RT) for $15 \mathrm{~min}$ and then permeabilized with PBS containing 0.5\% Triton X-100 (Thermo Fisher Scientific) for $15 \mathrm{~min}$. Cells were blocked with $10 \%$ donkey serum in PBS containing 1\% BSA and $0.1 \%$ Triton $\mathrm{X}-100$ at RT for $60 \mathrm{~min}$. Primary and secondary antibodies were diluted (see Supplementary Table S3 for details) in $1 \%$ BSA/0.1\% Triton X-100/PBS. Samples were incubated with primary antibodies at $4{ }^{\circ} \mathrm{C}$ overnight and with secondary antibodies at RT in the dark for $60 \mathrm{~min}$. Nuclei were stained with DAPI (1:2500) for $2 \mathrm{~min}$ and then samples were mounted in ProLong Gold (Thermo Fisher Scientific) and stored in the dark at RT. A Zeiss microscope (LMS700) and the ZEN 3.1 (blue edition) software were used for image acquisition and analysis.

\section{Flow cytometry analysis}

For CXCR4 staining, cells were harvested by dissociation to a single cell suspension with Versene. Cells were first incubated with Zombie violet (1:1000, Biolegend) at RT in the dark for $15 \mathrm{~min}$ to differentiate between live and dead cells. Cell pellets were then incubated with a PEconjugated anti-CXCR4 antibody (mouse PE, 1:200, BD Biosciences) or its isotype control at $4{ }^{\circ} \mathrm{C}$ for $30 \mathrm{~min}$ (see supplemental Table S3 for details). For GFP or ZsGreen analysis, cells were harvested by dissociation to single cell suspension using Versene and directly used for flow cytometry analysis.

All cells were analyzed using a Gallios flow cytometer (Beckman Coulter) and the Kaluza Analysis software (Beckman Coulter).

\section{Lactate dehydrogenase cytotoxicity assay and cell counting}

LDH cytotoxicity analysis was performed using the Cytotoxicity Detection Kit (LDH) (Roche) following the manufacturer's instructions. Briefly, supernatants of transduced and control cells were harvested every day for 3 days. A cell lysate control was made using a well of not transduced cells lysed in 1\% Triton X-100 solution. Fresh E8 medium constituted the blank control. Supernatants, blank, and lysis controls were centrifuged at $5000 \mathrm{rpm}$ for $3 \mathrm{~min}$ to remove cells and cell debris. Then, supernatants $(100 \mu \mathrm{l} / \mathrm{each})$ were distributed in $\mathrm{du}$ plicate in a 96-well plate. One hundred microliters of reaction mixture containing the catalyst and the dye solution was added to each well, and the plate was incubated in the dark at RT for $15 \mathrm{~min}$. Absorbance was measured at $492 \mathrm{~nm}$ using a Varioskan Flash reader (Thermo Fischer Scientific).

Cells were counted manually using a Malassez counting chamber after dissociation to single cells using Versene.

\section{Differentiation to definitive endoderm}

hiPSC were differentiated to definitive endoderm as per Ahmed et al. [45]. Briefly, 16 to $18 \mathrm{~h}$ before differentiation induction, cells were plated as single cells at 80000 cells $/ \mathrm{cm}^{2}$ in 24- or 6-well plates in E8 medium supplemented with $10 \mu \mathrm{M}$ Y-27632. Differentiation was induced by replacing the E8 medium with RPMI 1640 (GIBCO) supplemented with B27 without vitamin A (GIBCO), $100 \mathrm{ng} / \mathrm{ml}$ activin A (Peprotech), $3 \mathrm{mM}$ CHIR-99021 (Tocris), and $10 \mu \mathrm{M}$ Y-27632. After $24 \mathrm{~h}$, the medium was changed to RPMI 1640 supplemented with B27 without vitamin A, $100 \mathrm{ng} / \mathrm{ml}$ activin A, and $250 \mathrm{nM}$ LDN-193189 (Miltenyi biotec). Cells were then incubated for another $24 \mathrm{~h}$ to obtain definitive endoderm.

\section{Differentiation to neural progenitors and transduction} hiPSC were differentiated to neural progenitors using the STEMdiff ${ }^{\mathrm{TM}}$ SMADi Neural Induction kit (STEMCELL), following the manufacturer's instructions. Briefly, differentiation was induced by plating hiPSC as single cells at 200,000 cells $/ \mathrm{cm}^{2}$ in 6 -well plates coated with Geltrex matrix in STEMdiff ${ }^{\mathrm{TM}}$ Neural Induction medium supplemented with SMADi and $10 \mu \mathrm{M}$ Y-27632. After $24 \mathrm{~h}$, the medium was changed to fresh STEMdiff ${ }^{\mathrm{TM}}$ Neural Induction medium supplemented with SMADi. Then, the medium was changed daily for 4 to 5 days before cell passaging. For this, cells were dissociated to single cell using Versene followed by plating 150,000 cells $/ \mathrm{cm}^{2}$ in 6-well plates coated with Geltrex matrix in STEMdiff ${ }^{\mathrm{TM}}$ Neural Induction medium supplemented with SMADi and $10 \mu \mathrm{M}$ Y-27632.

The day prior to transduction, neural progenitors were dissociated to single cell using Versene and 125,000 cells $/ \mathrm{cm}^{2}$ were plated in 48 -well plates coated with Geltrex matrix in STEMdiff ${ }^{\mathrm{TM}}$ Neural Induction medium supplemented with SMADi and $10 \mu \mathrm{M} \mathrm{Y}$ 27632. Two hours before transduction, the medium was changed to fresh STEMdiff ${ }^{\mathrm{TM}}$ Neural Induction medium supplemented with SMADi and $10 \mu \mathrm{M}$ Y-27632. Transduction was performed using LentiFlash ${ }^{\circledR}$ particles in STEMdiff $^{\mathrm{TM}}$ Neural Induction medium supplemented with SMADi, $10 \mu \mathrm{M}$ Y-27632, and $8 \mu \mathrm{g} / \mathrm{ml}$ polybrene for 16 to $18 \mathrm{~h}$ before changing the medium. 


\section{Statistical analysis}

Data are presented as the mean \pm SEM. Differences were evaluated using the two-way ANOVA, Dunnett test. Statistical analyses were performed with GraphPad Prism. A value of $P \leq 0.05$ was considered to be significant.

\begin{abstract}
Abbreviations
Cas9: CRISPR-associated protein 9; CDNA: Complementary DNA; CCDC40: Coiled-coil domain containing 40; COPD: Chronic obstructive pulmonary disease; CRISPR: Clustered regularly interspaced short palindromic repeats; CXCR4: C-X-C chemokine receptor type 4; ddPCR: Droplet digital PCR; DSB: Double-strand breaks; hiPSC: Human induced pluripotent stem cells; hPSC: Human pluripotent stem cells; HRMA: High-resolution melting analysis; ICE: Interference of CRISPR edits; IDRV: Integration-deficient retroviral vector; ILV: Integrative lentiviral vector; LDH: Lactate dehydrogenase; LFZsGreen: LentiFlash ${ }^{\oplus}$ particles containing the fluorescent reporter ZsGreen mRNA; LVLP: Lentivirus-like particles; MCIDAS: Multiciliate differentiation and DNA synthesis associated cell cycle protein; MFI: Mean fluorescent intensity; MMEJ: Micro-homology end-joining; NHEJ: Non-homologous end-joining; NT: Not transduced; OT: Off-target; PCD: Primary ciliary dyskinesia; PFV: Prototype foamy virus; qPCR: Quantitative PCR; sgRNA: Single guide RNA; SIN: Self-inactivating; RRE: Rev-responsive element; RT: Room temperature; TRAC: T cell receptor alpha constant; TU: Transduction unit; VSV-G: Vesicular stomatitis virus envelope glycoprotein; WPRE: Woodchuck hepatitis virus post-transcriptional regulatory element; WT: Wild type allele
\end{abstract}

\section{Supplementary Information}

The online version contains supplementary material available at https://doi. org/10.1186/s12915-021-01214-X.

\footnotetext{
Additional file 1: Figs. S1-S11. Supplementary Figure S1.

Transduction of the HYO3 hiPSC line with LF-ZsGreen particles allows transient ZsGreen expression and does not affect pluripotency. Supplementary Figure S2. LF-ZsGreen particles allow the highly efficient delivery of RNA in different hiPSC lines. Supplementary Figure S3. Characterization of the HY03-GFP non-clonal reporter hiPSC line. Supplementary Figure S4. NGS analysis of DNAH5 indel size distribution. Supplementary Figure S5. LentiFlash ${ }^{\oplus}$ particle-based transduction of the CRISPR/Cas9 system to target the GFP fluorescent reporter sequence in a HCT116-GFP cell line that contains one GFP copy per cell. Supplementary Figure S6. Characterization of hiPSC clones in which DNAH5 or MCIDAS was knocked out by CRISPR/Cas9 gene editing using the LentiFlash ${ }^{\oplus}$ system. Supplementary Figure S7. LentiFlash ${ }^{\oplus}$ particle-based transduction of the CRISPR/Cas9 components to target specific genes results in high indel formation in different hiPSC lines. Supplementary Figure S8. Interallelic gene conversion following iPSC electroporation and following LentiFlash ${ }^{\oplus}$ transduction of neural progenitors obtained from the PCD_02:30 hiPSC line results. Supplementary Figure S9. Characterization of hiPSC clonal lines harboring DNAH5 heterozygous mutations. Supplementary Figure S10. Specifically targeting the wild-type allele in hiPSC clones harboring a DNAH5 heterozygous mutation results in interallelic gene conversion. Supplementary Figure S11. Schematic representation of the expression cassettes carried by the plasmids used to produce the integrative lentiviral vector (ILV) that expresses the GFP reporter and of the expression cassettes carried by the plasmids used to produce non-integrative lentiviral particles (LentiFlash ${ }^{\oplus}$ ) that express the ZsGreen reporter or the CRISPR/Cas9 systems. Supplementary Tables S1-3. Supplementary Table S1. sgRNA sequences. Supplementary Table S2. PCR primers. Supplementary Table S3. antibodies
}

\section{Acknowledgements}

We wish to thank Montpellier Rio Imaging for access to their flow cytometry facilities (http://www.mri.cnrs.fr/en/). We thank Elena Hauser and Marie Bouaud for technical help and Véronique Pantesco for helping in the amplicon deep sequencing experiment.

\section{Authors' contributions}

J.M., C.N.V., A.N., C.B., M.F., E.A., N.M, and F.S. performed the experiments. H.P. and A.L. performed the NGS. J.M. designed the experiments. C.D., N.M., A.I, R.G., S.A. and J.D.V. helped with the experiment design. C.D., N.M., A.I., R.G., F.S., L.L., and P.B. contributed to the development of the LentiFlash vectors used in the experiments. M.F., R.G., P.B., A.B., and S.A. revised the manuscript. J.M., C.D., N.M., A.I., and J.D.V. wrote the manuscript. All authors read and approved the final manuscript.

\section{Funding}

This work was supported by grant FDM20170638083 and by the "Investissement d'Avenir" program managed by the Agence Nationale pour la Recherche (contract ANR-10-INBS-09) (MGX).

\section{Availability of data and materials}

The datasets analyzed in the current study are available from the corresponding author.

\section{Declarations}

Ethics approval and consent to participate Not applicable.

\section{Consent for publication}

All authors read and approved the final manuscript.

\section{Competing interests}

S.A. and J.D.V. filed a patent entitled "Non-invasive methods for assessing genetic integrity of pluripotent stem cells", priority number: EP20150306389, and are co-founder and scientific advisor of Stem Genomics S.A.S. that acquired the exploitation rights of this patent. C.D., N.M., A.I., R.G., F.S., L.L., and P.B. work for Flash Therapeutics. J.M., C.N.V., C.B., M.F., E.A., and A.B. declare that they have no competing interests.

\section{Author details}

'IRMB, Univ Montpellier, INSERM, CHU Montpellier, Hôpital St Eloi, 80 avenue Augustin Fliche, 34295 Montpellier, France. ${ }^{2}$ Flash Therapeutics, Toulouse, France. ${ }^{3}$ Univ. Montpellier, CNRS, INSERM, Montpellier, France. ${ }^{4}$ MGX-Montpellier GenomiX, Univ. Montpellier, CNRS, INSERM, Montpellier, France. ${ }^{5}$ PhyMedExp, Univ Montpellier, INSERM, CHU Montpellier, Montpellier, France. ${ }^{6}$ Department of Cell and Tissue Engineering, Univ Montpellier, CHU Montpellier, Montpellier, France.

Received: 6 April 2021 Accepted: 2 December 2021 Published online: 07 January 2022

\section{References}

1. Rowe RG, Daley GQ. Induced pluripotent stem cells in disease modelling and drug discovery. Nat Rev Genet. 2019;20:377.

2. Shi Y, Inoue H, Wu JC, Yamanaka S. Induced pluripotent stem cell technology: a decade of progress. Nat Rev Drug Discov. 2017;16(2):115-30. https://doi.org/10.1038/nrd.2016.245.

3. Hockemeyer $D$, Jaenisch R. Induced pluripotent stem cells meet genome editing. Cell Stem Cell. 2016;18(5):573-86. https://doi.org/10.1016/j.stem.201 6.04.013.

4. Mianné J, Bourguignon C, Nguyen Van C, Nguyen van C, Fieldès M, Nasri A, et al. Pipeline for the generation and characterization of transgenic human pluripotent stem cells using the CRISPR/Cas9 technology. Cells. 2020;9(5). https://doi.org/10.3390/cells9051312.

5. Haapaniemi E, Botla S, Persson J, Schmierer B, Taipale J. CRISPR-Cas9 genome editing induces a p53-mediated DNA damage response. Nat Med. 2018;24(7):927-30. https://doi.org/10.1038/s41591-018-0049-z.

6. Ihry RJ, Worringer KA, Salick MR, Frias E, Ho D, Theriault K, et al. p53 inhibits CRISPR-Cas9 engineering in human pluripotent stem cells. Nat Med. 2018; 24(7):939-46. https://doi.org/10.1038/s41591-018-0050-6.

7. Li XL, Li GH, Fu J, Fu YW, Zhang L, Chen W, et al. Highly efficient genome editing via CRISPR-Cas9 in human pluripotent stem cells is achieved by transient BCL-XL overexpression. Nucleic Acids Res. 2018;46(19):10195-215. https://doi.org/10.1093/nar/gky804.

8. Yu X, Liang X, Xie H, Kumar S, Ravinder N, Potter J, et al. Improved delivery of Cas9 protein/gRNA complexes using lipofectamine 
CRISPRMAX. Biotechnol Lett. 2016;38(6):919-29. https://doi.org/10.1007/ s10529-016-2064-9.

9. Roberts B, Hendershott MC, Arakaki J, Gerbin KA, Malik H, Nelson A, et al. Fluorescent gene tagging of transcriptionally silent genes in hiPSCs. Stem Cell Reports. 2019;12(5):1145-58. https://doi.org/10.1016/j. stemcr.2019.03.001.

10. Mitzelfelt KA, McDermott-Roe C, Grzybowski MN, Marquez M, Kuo CT, Riedel $\mathrm{M}$, et al. Efficient precision genome editing in iPSCS via genetic co-targeting with selection. Stem Cell Reports. 2017;8(3):491-9. https://doi.org/10.1016/j. stemcr.2017.01.021.

11. Martin RM, Ikeda K, Cromer MK, et al. Highly efficient and marker-free genome editing of human pluripotent stem cells by CRISPR-Cas9 RNP and AAV6 donor-mediated homologous recombination. Cell Stem Cell. 2019;24: 821-828.e5.

12. Kim S, Kim D, Cho S-W, Kim J, Kim J-S. Highly efficient RNA-guided genome editing in human cells via delivery of purified Cas9 ribonucleoproteins. Genome Res. 2014;24(6):1012-9. https://doi.org/10.1101/gr.171322.113.

13. Geng BC, Choi KH, Wang SZ, Chen P, Pan XD, Dong NG, et al. A simple, quick, and efficient CRISPR/Cas9 genome editing method for human induced pluripotent stem cells. Acta Pharmacol Sin. 2020;41(11):1427-32. https://doi.org/10.1038/s41401-020-0452-0.

14. Xu X, Gao D, Wang P, Chen J, Ruan J, Xu J, et al. Efficient homologydirected gene editing by CRISPR/Cas9 in human stem and primary cells using tube electroporation. Sci Rep. 2018;8(1):11649. https://doi.org/10.1038/ s41598-018-30227-W.

15. Lu B, Javidi-Parsijani P, Makani V, Mehraein-Ghomi F, Sarhan WM, Sun D, et al. Delivering SaCas9 mRNA by lentivirus-like bionanoparticles for transient expression and efficient genome editing. Nucleic Acids Res. 2019, 47(8):e44. https://doi.org/10.1093/nar/gkz093.

16. Ortinski PI, O'Donovan B, Dong X, Kantor B. Integrase-deficient lentiviral vector as an all-in-one platform for highly efficient CRISPR/Cas9-mediated gene editing. Mol Ther Methods Clin Dev. 2017;5:153-64. https://doi.org/1 0.1016/j.omtm.2017.04.002.

17. Mock U, Riecken K, Berdien B, Oasim W, Chan E, Cathomen T, et al. Novel lentiviral vectors with mutated reverse transcriptase for mRNA delivery of TALE nucleases. Sci Rep. 2014;4(1):6409. https://doi.org/10.1038/srep06409.

18. Lindel F, Dodt CR, Weidner N, Noll M, Bergemann F, Behrendt R, et al. TraFo-CRISPR: enhanced genome engineering by transient foamy virus vector-mediated delivery of CRISPR/Cas9 components. Mol Ther Nucleic Acids. 2019;18:708-26. https://doi.org/10.1016/.omtn.2019.10.006.

19. Knopp Y, Geis FK, Heckl D, Horn S, Neumann T, Kuehle J, et al. Transient retrovirus-based CRISPR/Cas9 all-in-one particles for efficient, targeted gene knockout. Mol Ther Nucleic Acids. 2018;13:256-74. https://doi.org/10.1016/j. omtn.2018.09.006

20. Prel A, Caval V, Gayon R, Ravassard P, Duthoit C, Payen E, et al. Highly efficient in vitro and in vivo delivery of functional RNAs using new versatile MS2-chimeric retrovirus-like particles. Mol Ther Methods Clin Dev. 2015;2: 15039. https://doi.org/10.1038/mtm.2015.39.

21. Ling S, Yang S, Hu X, Yin D, Dai Y, Qian X, et al. Lentiviral delivery of copackaged Cas 9 mRNA and a Vegfa-targeting guide RNA prevents wet agerelated macular degeneration in mice. Nat Biomed Eng. 2021;5(2):144-56. https://doi.org/10.1038/s41551-020-00656-y.

22. Yin D, Ling S, Wang D, Dai Y, Jiang H, Zhou X, et al. Targeting herpes simplex virus with CRISPR-Cas9 cures herpetic stromal keratitis in mice. Nat Biotechnol. 2021;39(5):567-77. https://doi.org/10.1038/s41587-020-00781-8.

23. Fieldes $M$, Ahmed E, Bourguignon C, Mianné J, Martin M, Arnould C, et al. Generation of the induced pluripotent stem cell line UHOMi002-A from peripheral blood mononuclear cells of a healthy male donor. Stem Cell Res. 2020:49:102037. https://doi.org/10.1016/.scr.2020.102037.

24. Ahmed E, Sansac C, Fieldes M, Bergougnoux A, Bourguignon C, Mianné J, et al. Generation of the induced pluripotent stem cell line UHOMi001-A from a patient with mutations in CCDC40 gene causing primary ciliary dyskinesia (PCD). Stem Cell Res. 2018;33:15-9. https://doi.org/10.1016/j.scr.2 018.09.019.

25. Campenhout CV, Cabochette P, Veillard AC, Laczik M, Zelisko-Schmidt A, Sabatel C, et al. Guidelines for optimized gene knockout using CRISPR/Cas9. Biotechniques. 2019;66(6):295-302. https://doi.org/10.2144/btn-2018-0187.

26. Lu Z, Yao X, Lyu P, Yadav M, Yoo K, Atala A, et al. Lentiviral capsid-mediated Streptococcus pyogenes Cas9 ribonucleoprotein delivery for efficient and safe multiplex genome editing. CRISPR J. 2021. https://doi.org/10.1089/ crispr.2020.0106
27. Lyu P, Lu Z, Cho SI, Yadav M, Yoo KW, Atala A, et al. Adenine base editor ribonucleoproteins delivered by lentivirus-like particles show high on-target base editing and undetectable RNA off-target activities. CRISPR J. 2021;4(1): 69-81. https://doi.org/10.1089/crispr.2020.0095.

28. Jonkman MF, Scheffer H, Stulp R, Pas HH, Nijenhuis M, Heeres K, et al. Revertant mosaicism in epidermolysis bullosa caused by mitotic gene conversion. Cell. 1997;88(4):543-51. https://doi.org/10.1016/S0092-8674 (00)81894-2

29. Javidi-Parsijani P, Lyu P, Makani V, Sarhan WM, Yoo KW, el-Korashi L, et al. CRISPR/Cas9 increases mitotic gene conversion in human cells. Gene Ther. 2020;27(6):281-96. https://doi.org/10.1038/s41434-020-0126-z.

30. Susani L, Castelli A, Lizier M, Lucchini F, Vezzoni P, Paulis M. Correction of a recessive genetic defect by CRISPR-Cas9-mediated endogenous repair. CRISPR J. 2018;1 (3):230-8. https://doi.org/10.1089/crispr.2018.0004.

31. Wu Y, Liang D, Wang Y, Bai M, Tang W, Bao S, et al. Correction of a genetic disease in mouse via use of CRISPR-Cas9. Cell Stem Cell. 2013;13(6):659-62. https://doi.org/10.1016/j.stem.2013.10.016.

32. Adikusuma F, Piltz S, Corbett MA, Turvey M, McColl SR, Helbig KJ, et al. Large deletions induced by Cas9 cleavage. Nature. 2018;560(7717):E8-9. https://doi.org/10.1038/s41586-018-0380-z.

33. Egli D, Zuccaro MV, Kosicki M, Church GM, Bradley A, Jasin M. Interhomologue repair in fertilized human eggs. Nature. 2018;560(7717):E5-7. https://doi.org/10.1038/s41586-018-0379-5.

34. Burgio G. Gene conversion following CRISPR/Cas9 DNA cleavage: an overlooked effect. Gene Ther. 2020;27(6):245-6. https://doi.org/10.1038/ s41434-020-0154-8.

35. Zuccaro MV, Xu J, Mitchell C, Marin D, Zimmerman R, Rana B, et al. Allelespecific chromosome removal after Cas9 cleavage in human embryos. Cell. 2020;183(6):1650-1664.e15. https://doi.org/10.1016/j.cell.2020.10.025.

36. Yoshimi K, Kaneko T, Voigt B, Mashimo T. Allele-specific genome editing and correction of disease-associated phenotypes in rats using the CRISPRCas platform. Nat Commun. 2014;5(1):4240. https://doi.org/10.1038/ ncomms5240.

37. Ma H, Marti-Gutierrez N. Park SW et al. Nature: Correction of a pathogenic gene mutation in human embryos; 2017.

38. Liang D, Gutierrez NM, Chen T et al. Frequent gene conversion in human embryos induced by double strand breaks. bioRxiv. 2020

39. Ma H, Marti-Gutierrez N, Park SW, et al. Ma et al. reply. Nature. 2018; 560(7717):E10-23. https://doi.org/10.1038/s41586-018-0381-y.

40. Canny MD, Moatti N, Wan LCK, et al. Inhibition of 53BP1 favors homologydependent DNA repair and increases CRISPR-Cas9 genome-editing efficiency. Nat Biotechnol. 2017.

41. Wilde JJ, Aida T, Del Rosario RCH, et al. Efficient embryonic homozygous gene conversion via RAD51-enhanced interhomolog repair. Cell. 2021;184: 3267-3280.e18.

42. Blanpain C, Mohrin M, Sotiropoulou PA, Passegué E. DNA-damage response in tissue-specific and cancer stem cells. Cell Stem Cell. 2011;8(1):16-29. https://doi.org/10.1016/j.stem.2010.12.012.

43. Fu X, Cui K, Yi Q, Yu L, Xu Y. DNA repair mechanisms in embryonic stem cells. Cell Mol Life Sci. 2017;74(3):487-93. https://doi.org/10.1007/s00018-01 6-2358-z.

44. Rocha CRR, Lerner LK, Okamoto OK, Marchetto MC, Menck CFM. The role of DNA repair in the pluripotency and differentiation of human stem cells. Mutation research. 2012

45. Ahmed $\mathrm{E}$, Fieldes $\mathrm{M}$, Bourguignon $\mathrm{C}$ et al. Differentiation of human induced pluripotent stem cells into functional airway epithelium. bioRxiv. 2020. Available from: https://doi.org/10.1101/2020.11.29.400358

46. Haeussler M, Schönig K, Eckert H, Eschstruth A, Mianné J, Renaud JB, et al. Evaluation of off-target and on-target scoring algorithms and integration into the guide RNA selection tool CRISPOR. Genome Biol. 2016;17(1):148. https://doi.org/10.1186/s13059-016-1012-2.

47. Osborn MJ, Webber BR, Knipping F, et al. Evaluation of TCR gene editing achieved by TALENs, CRISPR/Cas9 and megaTAL nucleases. Mol Ther. 2015.

48. Schumann $\mathrm{K}$, Lin $\mathrm{S}$, Boyer E, Simeonov DR, Subramaniam M, Gate RE, et al. Generation of knock-in primary human T cells using Cas9 ribonucleoproteins. Proc Natl Acad Sci U S A. 2015;112(33):10437-42. https://doi.org/10.1073/pnas.1512503112.

49. Mali P, Aach J, Stranges PB, Esvelt KM, Moosburner M, Kosuri S, et al. CAS9 transcriptional activators for target specificity screening and paired nickases for cooperative genome engineering. Nat Biotechnol. 2013;31(9):833-8. https://doi.org/10.1038/nbt.2675. 
50. Chao JA, Patskovsky Y, Almo SC, Singer RH. Structural basis for the coevolution of a viral RNA-protein complex. Nat Struct Mol Biol. 2008;15(1): 103-5. https://doi.org/10.1038/nsmb1327.

51. Bouillé P, Pages JC, Gayon R. Retroviral particle comprising at least two encapsidated nonviral RNAs. US PATENT. 2017 US20180135025A1.

52. Bouillé $P$, Gayon R, Lamouroux L, Iche A. Particle for the encapsidation of a genome engineering system. US PATENT. 2016 US10870865B2.

53. Hsiau T, Conant D, Rossi N et al. Inference of CRISPR Edits from Sanger Trace Data. bioRxiv. 2018

54. Clement K, Rees H, Canver MC, Gehrke JM, Farouni R, Hsu JY, et al. CRISPResso2 provides accurate and rapid genome editing sequence analysis.[letter]. Nat Biotechnol. 2019;37(3):224-6. https://doi.org/10.1038/s41 587-019-0032-3.

55. Assou S, Girault N, Plinet M, Bouckenheimer J, Sansac C, Combe M, et al. Recurrent genetic abnormalities in human pluripotent stem cells: definition and routine detection in culture supernatant by targeted droplet digital PCR. Stem Cell Reports. 2020;14(1):1-8. https://doi.org/1 0.1016/j.stemcr.2019.12.004.

\section{Publisher's Note}

Springer Nature remains neutral with regard to jurisdictional claims in published maps and institutional affiliations.

Ready to submit your research? Choose BMC and benefit from:

- fast, convenient online submission

- thorough peer review by experienced researchers in your field

- rapid publication on acceptance

- support for research data, including large and complex data types

- gold Open Access which fosters wider collaboration and increased citations

- maximum visibility for your research: over $100 \mathrm{M}$ website views per year

At BMC, research is always in progress.

Learn more biomedcentral.com/submissions 